\title{
The Potency of Dental Mesenchymal Stem Cells: A Short Review of the Literature
}

\author{
Marina Miteva ${ }^{\star, \dagger}$ \\ Faculty of Dental Medicine, Medical University-Sofia, Bulgaria \\ ODOI: https://doi.org/10.15520/jcmro.v2i08.194
}

Accepted 19-08-2019; Received 14-08-2019; Publish Online 19-08-2019

\author{
Reviewed By: Dr. \\ SEYDOU MBAYE \\ Department: \\ Reviewer/CMRO
}

\begin{abstract}
There is a pool of nondifferentiated mesenchymal stem cells (MSC) in human dental tissues. These cells are capable in appropriate conditions to differentiate into various cell types. Dental MSC are ideal candidates for stem cell regenerative therapy. However, further research is required before their routine application in the clinical practice.
\end{abstract}

Key words: Dental Stem Cells-Stem Cell Differentiation-Stem Cell Markers

\section{INTRODUCTION:}

Nondifferentiated stem cells are known to be presented all over the human body. Dental structures represent a promising source of stem cells due to the easy access and lack of legal considerations about the biomaterials collection. Nowadays, several different types of dental mesenchymal stem cells (MSC) have been isolated and thorough investigation of their properties has been carried out [1]. These are stem cells from dental pulp of permanent teeth (DPSCdental pulp stem cells) and temporary teeth (SHED-stem cells from human exfoliated deciduous teeth), periodontal ligament stem cells (PDLSC), stem cells from apical papilla (SCAP) and stem cells from pericoronal follicular tissues (DFSC-dental follicle stem cells) [1, 2]. All of them are capable of self-renewal, colonogenicity and multilineage differentiation $[2,3]$.

- DPSC - were first isolated in 2000 by Gronthos et al. [4] from dental pulp of intact third molars. These cells are able to differentiate into odontoblast-like cells and to regenerate the pulp-dentine complex after implantation in immunocompromised mice [4]. DPSC have properties quite similar to bone marrow mesenchymal stem cells (BMSC). Aappropriate in vitro conditions significantly affect their phenotype [5].

- SHED are found in dental pulp of deciduous teeth with advanced root resorption [6]. Stem cells with positive expression of wide range markers have been identified in the pulp of deciduous teeth, revealing the presence of heterogenic cell population [7]. SHED can differentiate to

\footnotetext{
* Corresponding author.

† Email:mia9580@yahoo.com
}

osteoblast-like and are able to initiate the formation of a bone-like matrix [6].

- PDLSC have been first isolated in 2004 by Seo et al. [8]. They have all the characteristics of stem cells and are able to differentiate into adipocytes, osteoblast-like cells and to form cementum-periodontal ligament-like complex in immunocompromised mice [8]. PDLSC are collected from the root surface of the extracted teeth, as well as from the dental socket wall. According to Wang et al. [9] these two types of cells vary in their differentiation potential, as cells isolated from the walls of the bone socket can lead to better regeneration of the alveolar bone compared to cells from the root surface. Various active molecules and growth factors are capable to modify their stem cell properties [10-13].

- SCAP are isolated from the apical papilla situated on the root apices of developing teeth [14]. They have a high potential of proliferation and differentiation into odontoblast-like cells, as they originate from nonmature dental structures that are still at very early stage of development [14].

- DFSC - The dental follicle is a sac that surrounds the tooth germ until the tooth has fully erupted. Precursor cells capable of differentiating into cementoblasts, osteoblasts and periodontal ligament cells have been isolated from human dental follicle [15].

\section{REGENERATIVE POTENTIAL OF DEN- TAL MESENCHYMAL STEM CELLS:}

In the past years, there have been increasing number of reports revealing the potential application of MSCs in the clinical practice $[16,17]$. Cells isolated from dental 


\section{The Potency of Dental Mesenchymal Stem Cells: A Short Review of the Literature}

tissues are a heterogeneous cell population consisting of stem/progenitor cells, fibroblasts, etc. [6, 18]. Isolation of primary stem cell cultures, followed by thorough characterization and investigation of their properties would lead to more predictable results of their in vivo application.

According to some authors, dental MSC have different ability of de novo tissues and structures formation [19]. DPSC, SHED and SCAP have the potential to initiate bone, cartilage, and pulpodentin complex regeneration, while PDLSC stimulate formation and regeneration of muscle tissue, tendons, and ligaments [19]. The ability of dental MSCs of bone regeneration makes them ideal candidated in the complex management of extensive periodontal bone defects. Their potential to differentiate into bone-like cells and to synthesize a bone matrix has been widely investigated [4] [8].

Regenerative osteogenic potential of dental MSC can be investigated in vitro after the addition of suitable active molecules in the cell culture media that can induce osteogenic differentiation. Wide number of studies report strong Alizarin red in MSC when cultivated in osteogenic differentiation media $[4,8]$. Other methods, like flow-cytometry markers expression also reveal specific differentiation ability in stem cells [20]. The addition of active substances such as vascular endothelial growth factor (VEGF), fibroblast growth factor (FGF) bone morphogenetic protein-bone morphogenetic protein (BMP), etc., in the cell culture media in vitro, affects significantly the differentiation processes [21-23]. BMP family have positive effect on osteogenesis $[21,23]$. There is already evidence in the literature of in vivo experiments that demonstrate the ability of BMP to stimulate bone regeneration in peri-implant tissues [24]. Lee et al. [24] report that VEGF stimulates the mineralization of PDL cells, whereas cell cultivation with FGF-2 has an inhibitory effect on the osteogenesis. Each growth factor is having different effects on cells [25]. Studies about the effects of growth factors on stem cells would contribute to their introduction in the clinic for the treatment of wide number pathological conditions associated with soft tissue destruction and bone resorption.

Although the functions of dental MSCs are well described in the literature $[2,4]$, reports about their effect in patients in vivo are still scarce. The goal of all MSC studies is their further successful clinical application. Conduction of wellplanned experiments, revealing in detaisl the optimal conditions for their proper functioning is needed [19].

\section{CONCLUSION}

MSC with high potential have been isolated from human dental tissues. However, little is known about their regenerative potential in vivo due to the lack of sufficient scientific data about their application in clinical trials. Further research is needed to clarify the effects of various molecules on dental MSC and to reveal the most appropriate conditions of stem cell therapy

\section{REFERENCES}

1. Akiyama K, Chen C, Gronthos S, Shi S. Lineage differentiation of mesenchymal stem cells from dental pulp, apical papilla, and periodontal ligament. Methods Mol Biol 2012; 887: 111-121.

2. Estrela C, Alencar AHGD, Kitten GT, Vencion EF, Gava E Mesenchymal Stem Cells in the Dental Tissues: Perspectives for Tissue Regeneration. Braz Dent J 2011; 22: 91-98

3. Huang GTJ, Gronthos S, Shi S. Mesenchymal stemcells derived from dental tissues vs. those from other sources: their biology and role in regenerative medicine. J Dent Res 2009; 88: 792-806.

4. Gronthos S, Mankani M, Brahim J, Robey PG, Shi S. Postnatal human dental pulp stem cells (DPSCs) in vitro and in vivo. Proc Natl Acad Sci U S A 2000; 97: 13625-13630.

5. Tsikandelova R, Mladenov P, Planchon S, Kalenderova S, Praskova M, Mihaylova Z, Stanimirov P, Mitev V, Renaut J, Ishkitiev N. Proteome Response of Dental Pulp Cells to Exogenous FGF8. J Proteomics, 2018, 183:14-24.

6. Miura M, Gronthos S, Zhao M, Lu B, Fisher LW, Robey PG, Shi S SHED: Stem cells from human exfoliated deciduous teeth. Proc Nat Acad Sci U S A 2003; 100: 5807-5812.

7. Ishkitiev, N., Mitev, V., Rashkova, M., Tsikandelova, R., Mihaylova, Z., Dimitrova, V., Mitova, N. Phenotypic characterization of deciduous teeth pulp stem cell populations. Problems of dental medicine. 2016. 42 (1): 31-38 (In Bulgarian).

8. Seo BM, Miura M, Gronthos S, Bartold PM, Batouli S, Brahim J, Shi S. Investigation of multipotent postnatal stem cells from human periodontal ligament. Lancet 2004; 364: 149-155.

9. Wang L, Shen H, Zheng W, Tang L, Yang Z, Gao Y, Jin Y. Characterization of stem cells from alveolar periodontal ligament. Tissue Eng Part A 2011; 17: 1015-1026.

10. Mihaylova Z, Ishkitiev N, Stanimirov P, Tsikandelova R, Mitev V, Gateva N, Aleksiev E. Effect of VEGF on stem cell and differentiation properties of periodontal ligament stem cells in vitro. Problems of dental medicine. 2017; 43(2): 39-46 (In Bulgarian)

11. Mihaylova Z, Tsikandelova R, Stanimirov P, Gateva N, Mitev V, Ishkitiev N. Role of PDGF-BB in proliferation, differentiation and maintaining stem cell properties of PDL cells in vitro. Arc Oral Biol. 2018; 1(85):1-9.

12. Mihaylova Z, Stanimirov P, Tsikandelova R, Ishkitiev N, Mitev V. Methods for Proliferation, Differentiation and Collagen Production Studies of PDL Stem Cells. Intl J Sci Res. 2017. 6(4):1104-1107.

13. Mihaylova, Z., Stanimirov, P., Mitev, V., Ishkitiev, N. Plateletderived products and periodontal ligament stem cells.Arc Stem Cell Res, 2015; 2, 1006.

14. Sonoyama W, Liu Y, Yamaza T, Tuan RS, Wang S, Shi S, Huang GTJ. Characterization of the apical papilla and its residing stem cells from human immature permanent teeth: A pilot study. J Endod 2008; 34 166-171.

15. Morsczeck C, Götz W, Schierholz J, Zeilhofer F, Kühn U, Möhl C, Hoffmann $\mathrm{KH}$. Isolation of precursor cells (PCs) from human dental follicle of wisdom teeth. Matrix Biol 2005; 24: 155-165.

16. Abdallah BM, Kassem M. Human mesenchymal stem cells: from basic biology to clinical applications. Gene Ther 2008; 15: 109-116.

17. Sensebe L, Krampera M, Schrezenmeier H. Mesenchymal stem cells for clinical application. Vox sang 2010; 98: 93-107.

18. Gronthos S, Brahim J, Li W, Fisher LW, Cherman N, Boyde A, Shi S. Stem cell properties of human dental pulp stem cells. J Dent Res 2002;81: 531-535.

19. Xiao L, Nasu M. From regenerative dentistry to regenerative medicine: progress, challenges, and potential applications of oral stem cells. Stem Cells Cloning 2014; 7: 89-99.

20. Shi S, Gronthos S. Perivascular niche of postnatal mesenchymal stem cells in human bone marrow and dental pulp. J Bone Miner Res 2003; 18: 696-704.

21. Hakki S S, Bozkurt B, Hakki E E, Kayis SA, Turac G, Yilmaz I, Karaoz E. Bone morphogenetic protein-2, -6 , and -7 differently regulate osteogenic differentiation of human periodontal ligament stem cells. J Biomed Mater Res, Part B Appl Biomater 2014; 102: 119-130. 
22. Lee J H, Um S, Jang J H, Seo B M. Effects of VEGF and FGF-2 on proliferation and differentiation of human periodontal ligament stem cells. Cell Tissue Res 2012; 348: 475-484.

23. Maegawa N, Kawamura K, Hirose M, Yajima H, Takakura Y, Ohgushi H. Enhancement of osteoblastic differentiation of mesenchymal stromal cells cultured by selective combination of bone morphogenetic protein-2 (BMP-2) and fibroblast growth factor-2 (FGF-2). J Tissue Engin Regener Med 2007; 1: 306-313.

24. Park SY, Kim KH, Gwak EH, Rhee SH, Lee JC, Shin SY, Seol YJ. Ex vivo bone morphogenetic protein 2 gene delivery using periodontal ligament stem cells for enhanced re-osseointegration in the regenerative treatment of peri-implantitis. J Biomed Mater Res Part A 2015; 103: 38-47.

25. Mihaylova Z, Mitev V, Stanimirov P, Isaeva A, Gateva N, Ishkitiev $\mathrm{N}$. Use of platelet concentrates in oral and maxillofacial surgery: an overview. Acta Odontol Scand 2017;75(1):1-11. 